Basic research is outside the farmer's scope, but he can put into practice some of the findings of research organizations; for example, those relating to the effects of fertilizers, improved yields of new varieties or stock, and disease treatment. State intervention is needed in many fields to secure the prosecution of research for the benefit of agriculture, and to make known its results. If increased and cheapened production is regarded as a necessity in the modern State, intervention of another kind is needed to free agriculture from some of the limitations imposed by its present structure; failing that, there is danger that the factory will replace the farm in the production of essential commodities.

The meeting was very well attended, and at the close Prof. A. Ferguson referred to possible research work that might be undertaken by the Division, such as a study of the development of nationalistic feeling, and the history of Westerm thought. Such interesting and important studies would be welcomed by many, but it may be suggested that they should not take precedence over the essential task of attacking concrete problems in a scientific way. Sir Daniel Hall's remarks on the necessity for State intervention in agriculture suggest that a suitable study would be the very old, but still very important, question of land tenure, of public control of the land and its utilization. Such a study, it might be objected, would inevitably lead to 'impact', that is, collision, with politics, but it need not be treated in a politicocontroversial way. What is needed are the reasoned judgments of trained scientific workers, who have no economic, political, social or other axes to grind, who are capable of submerging the embedded sentiments, of which Prof. Barker spoke (except that of justice), and above all, who will take the vow of placing the common good above all the lesser loyalties, like political party, social class, and the 'old school tie'.

E. H. T.

\title{
Hydrogenation
}

D URING May 24-26, a conference was held in Paris under the auspices of the five chemical societies which share the amenities of the Maison de la Chimie there. The selected subject was the various aspects of hydrogenation. This is the second occasion on which the same five societies have co-operated. An average attendance of more than three hundred was attracted. The meetings commenced at 4.30 in the afternoon, so enabling the participants to go about their ordinary affairs during the working day. The chief figure at the meeting was Prof. Sabatier of Toulouse, still hale and hearty at eighty-four years of age : his original researches are recognized as having given the first impetus to the study of all subsequent hydrogenation reactions, some of which are technically in the forefront of world interest to-day. The presidents of four of the societies presided in turn over the sittings.

The conference appropriately began with a paper from Sabatier, largely of an historical nature, relating to the addition of hydrogen to unsaturated compounds in presence of nickel. Prof. Paul followed with an account of the Raney nickel catalyst. The evening discourse delivered by Prof. Aubel, of Paris, dealt with the general phenomenon of hydrogenation in biology. On the next afternoon, Prof. N. V. Ipatieff, who now holds a chair at the Northwestern University of Chicago, spoke on the use and advantages of copper and copper chromium catalysts for the hydrogenation of benzene and its derivatives, describing work which is being followed with considerable interest. The following paper was delivered by Dr. E. F. Armstrong, who dealt fully with the technical and industrial development of hydrogenation, first in regard to fat hardening, which has now largely become standard practice; afterwards he indicated the methods of manufacture of hydrogen and the approximate cost of this gas, describing also the line of attack which is being followed in the conversion of water gas into petroleum hydrocarbons, and of coal, under pressure, into methane.

At the conclusion of the meeting, Messrs. Ipatieff and Armstrong were each presented with a Chevreul Medal in recognition of their labours in their respective fields of inquiry. The meeting ended with a banquet held in one of the large lecture rooms of the Maison de la Chimie, which readily lent itself to this conversion and was provided with the necessary auxiliary accommodation behind the scenes. The excellent facilities provided here for our French colleagues are the cause of renewed admiration and envy on every occasion we avail ourselves of them. They enabled a first-class banquet with wines to be staged for the modest charge of 60 francs.

The third day was primarily concerned with the official celebration of the twenty-fifth birthday of the Société de Chimie Biologique, but even here the role of active hydrogen was not overlooked, being made the subject of a paper by Prof. Thunberg of Lund.

\section{Work of the Cornish Engineers}

N the form of a reprint from the Journal of the
Royal Institution of Cornwall, there has been
published at the Royal Printeries, Truro, a paper
by W. Tregoning Hooper entitled "The World's Debt
to Cornish Engineers", one of the aims of which is
to commemorate the historic experimental trials of
the Austen's 80 in. Cornish pumping engine. At these
trials, this engine established a record of accomplish- ment which demonstrated to men of science, engineers and economists the great potentialities of the power of steam, and the occasion is, therefore, a fitting one to be recalled and celebrated.

In the year 1835, in collaboration with his chief engineer, West, Joseph Thomas Treffry erected a new 80 in. engine and it was stated to have done a duty of nearly 98 million foot-pounds of work per 